\title{
Towards an Adaptive e-Learning Solution based on Ontologies and Competencies Approach
}

\author{
Mohamed GHAILANI \\ Laboratory LIST \\ FST- Tangier \\ Tangier-Morocco
}

\author{
Jaber EL BOUHDIDI \\ Laboratory LIST \\ FST Tangier \\ Tangier-Morocco
}

\author{
Abdelhadi FENNAN \\ Laboratory LIST \\ FST- Tangier \\ Tangier-Morocco
}

\begin{abstract}
This paper presents a novel solution for modeling professional bimodal hybrid training based on the ontological engineering and the pedagogical competencies approach. It is an educational solution for personalizing learning under the frame of vocational trainings and providing learners two learning scenarios: The first is called free, where the learner can choose a competency level that he aims to develop. And the second is called guided, where the learner must obey the instructions of the system to develop his competencies as part of a Certificate or diploma training.

This solution fits in the context of the development of Adaptive Learning Systems. It is based on the principle of dynamic composition of learning units and the choice of integration situations to deliver learning sessions to meet the needs of learners and reflect their preferences for learning styles. In addition, and to create a coherent model, we used the example of the Regional Centers of trades, education and training of Morocco (CRMEF) to train future teachers.
\end{abstract}

\section{Keywords}

Ontologies, Professional Hybrid Bimodal Training, Competencies approach, learning scenarios.

\section{INTRODUCTION}

For a long time, we were in a presential learning logic, whereas, with the emergence of information and communication technologies, we go more and more to a distanciel learning logic. Distance learning offers training without spatio-temporal constraints on specialized concepts. Several LCMS and platforms have been developed for this purpose; however, they quickly faced with two major problems: First, the learning activities they deliver are often fragmented to specific learning and monitored separately by learners without establishing links between them and make meaningful global conceptualizations to them. In addition, their evaluation is far from being complete because the latter is often associated with very specific knowledge tranches. However, the integration of knowledge and its mobilization in complex problem situations are essential. Second, most of the proposed solutions apply the philosophy of "one-size-fits all", that is to say; the same resources are provided for all learners while they do not all have either the same needs or the same knowledge or the same learning styles.

In this regard, a cruel need of a flexible, hybrid and more complete solution is flagrant. To meet this need, we propose in this paper the modeling of an adaptive solution based on the ontological engineering and the competencies pedagogical approach to deliver tailored learning situations in vocational training. Regional Centers of trades, education and training of
Morocco (CRMEF) are an example. These latter adopt the competency-based approach in their training. Indeed, the competency-based approach aims to develop learners' skills to adapt with problems situations that cross their path of learning. It offers solutions to the above limits by providing learners with integration situations allowing them to mobilize and use wisely what they have learned, which will allow them to make connections between the apprehended concepts and thus to create global and meaningful representations. Especially, proposing learning situations which are adapted to the learners' profiles and guided by tutors agents can strongly guarantee their success and increase their motivation.

The laureates of CRMEF and future teachers always need training to keep pace with technological development and educational news. Doing them presential training requires a large budget and often leads to the disruptions of students owing to the suspensions of their courses. To address these institutional needs as well as those of the apprentices, we have proposed a solution that fits in the frame of the continuity of our previous works [1], [2], [3]. Our previous works focused on the design and the development of an intelligent architecture based on the approach by objectives for the generation of personalized learning paths to support university students. Students may directly target objectives to develop and run personalized learning paths. The present work aims to make cohabitation between the two approaches, the approach by objectives and the approach by competencies in a solution offering the apprentices the opportunity to develop competencies in the frame of vocational training or a specific competencies level while basing on adaptation techniques used in our previous works to provide them with adaptive learning sessions.

Adapting the learning sessions to the learners' profiles requires the collection of their information and particularly those that fall into the learning process. Among the most important learners' information we find their learning styles. These latter must be determined by the system in order to exploit them at the time of the presentation of the learning sessions. In addition, educational resources should be described using standards to ensure their reuse. The Semantic Web ontologies enable a semantic description of knowledge and are seen the most appropriate for information management of the online learning systems. Their use in a learning system ensures a better management of the resources and the competencies of learners. As part of this solution we have developed a number of ontologies so that the learners' information are grouped in a learners' ontology, those of resources in the resources' ontology based on LOM standard and training's competencies in the competencies' ontology based on the IMS-RDCEO standard. 
The rest of this paper is organized as follows: Section 2 reviews the related works and their intersection with the our own work, section 3 presents the model of the learner as a central element of the learning systems, section 4 presents the modeling of training according to the competency-based approach, section 5 presents the training scenarios and finally, section 6 presents the evaluation and support process as part of this solution.

\section{RELATED WORKS}

The objective of this section is to present the research's works related to pedagogical engineering according to competencybased approach. Several authors are interested in this approach and its integration into the modeling of learning environments. Van Merriënboer offers a baptized model 4C/ID which aims for a learning that is based on the development of the competencies [5]. Sluijsmans and his collaborators go out from the fact that learning environments should be designed on basing on a holistic approach to a learning aiming to solve problems [6].Their works focused on the design of examples of learning environment according to the competency-based approach. Furthermore, the research's works based on competency engineering in the computerized learning environments are carried some years ago at the Research Centre of the Tele-university LICEF. In its "engineering method of learning systems" (MISA), Paquette includes a step of specifying the competencies covered in the learning system [7].The conceptual framework and the technique he proposes to do this is described in his book Modeling knowledge and competencies [8].Paquette also proposed an approach to make available to learners and people ensuring their supervision computerized tools in order to track their progress in a progressive scale associated to each competency. A series of computerized tools of competency management were proposed by this author and his collaborators [9] and [10].

Moreover, Moulet proposed a competency oriented learner's model and integrating its productions [11].Other studies have put the focus on competency assessment in distance learning environments, activities of the self-assessment of learners' competencies have been designed and integrated into pedagogical scenarios to equip the learners and perfect their competencies [12] and [13]. InfoCompétences+ being the example, whether it is a tool originally designed to assess the information competencies of the learners and incorporates a database containing a referential of competencies related to a field [14].This will allow them to monitor the evolution of their competencies and act according to their needs.

In other words, the competencies' referential have become inevitable in all levels of education and especially in the areas of professional certification. The latter represent a list of competencies organized and explained so as to prepare a specific professional profile. Think here in the training program of the Quebec school (primary, secondary and teacher' initial training), and also that of teacher trainees in Morocco. In electronic training, the majority of referential is presented on websites in a format not promoting the sharing and reuse by a community of interested. It is for this reason that restructuring is required. In this paper, we present the elements to consider when designing competencies' referential based on norms and standards in order to promote their visibility and sharing. The use of standards, however, does not solve all problems, because some characteristics of competency referential are not addressed by these standards, which require adaptations [15].In addition, several ways to develop a competency referential exist [16] and [17].

\section{MODELLING THE LEARNER: NEEDS AND SPECIFICATIONS}

\subsection{Model of the Learner and Learning Styles}

The learner model is an essential component of adaptive learning systems. It provides them with relevant information to adapt the learning to the knowledge, competencies, learning objectives, characteristics and preferences of learners. Two terms are used in the literature and with different connotations: the model of the learner and the profile of the learner. However, in the context of this paper, we consider that the two names are the same and refer to all information necessary for the system to perform the adaptation of learning. The learner model must characterize his area of interest and all his specific features helping the adaptive system to provide learners with concepts more adequately.

Furthermore, two kinds of learner model have emerged in the literature: the recovery model and the perturbation model. Recovery model uses the representation of knowledge of a domain to model those of the user. He considers the knowledge of the learner as a subset of an expert knowledge and it builds gradually as the user browses educational resources, by storing the visited areas. The recovery model can be represented by a set of concept-value pairs; each concept is characterized by a degree of binary knowledge, qualitative or quantitative. As to the perturbation model or Buggy, it relies on a method of determining the correct and incorrect behavior of a learner with a system, diagnoses errors and depending on the diagnosis obtained, a new lesson is generated to correct prospective errors or confusions of the learner [18].

Especially, to ensure the sharing and the reuse of learner profiles from different platforms, several standards and specifications have been developed in the literature, include for example, the standard PAPI (Public And Private Information for learners) and the standard IMS-LIP (Instructional Management Systems for Learner Information Package). As part of this solution, we used the standard IMSLIP because it sees more appropriate to our goals.

\subsection{Learning Styles}

Learning styles represent individual differences which play a crucial role in learning. Learning styles refer to the characteristics of an individual when he learns, i.e. the specific way to approach a learning task, learning strategies activated when performing a task. Several definitions of learning styles have been proposed in the literature, we retain that of Beshuizen et al. "A predisposition on the part of some students to adopt a particular learning strategy regardless of the specific requirements of the learning task".

Many researchers have shown the importance of taking into consideration the students' learning styles when adapting learning sessions. Indeed, because of the interest by researchers in the field of learning styles, several models of learning styles were born. In this article we retained the model of Felder and Silverman [2].The latter classifies learners according to the means used to collect and process information, four dimensions were identified: i) Active / Reflective, ii) Sensing / Intuitive, iii) Visual / Verbal, and finally iv) Sequential / Global.

\subsection{Learners Profiles' Ontology}

For a description of learner' profiles we used semantic web ontologies by the benefits they offer in terms of representation and formal semantics and knowledge description. The learner 
model is designed using ontology. This model allows representing different information (personal, of learning and professional) for the acquisition of new competencies. To facilitate management we divided the learner profile into three profiles: personal profile that stores static information of the learner model, learning sub-profile that manages preferences and learning styles and professional sub-profile that stores his competencies, his objectives and productions. The following table summarizes representative elements of each sub-profile.

Table1.Decomposition of learner profile to three subprofiles

\begin{tabular}{|c|c|c|c|}
\hline & \multicolumn{3}{|c|}{ Learner model } \\
\hline 兘 & 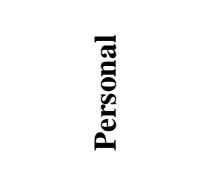 & 冓 & 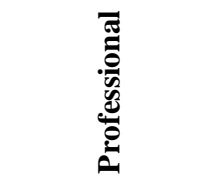 \\
\hline 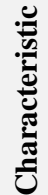 & $\begin{array}{c}\text {-Name } \\
\text {-Family name } \\
\text { - Date of birth } \\
\text {-Specialization } \\
\text {-Etc. }\end{array}$ & $\begin{array}{l}\text { - Preferences } \\
\text { - Learning Style } \\
\text { - } \quad \text { - Etc. }\end{array}$ & $\begin{array}{l}\text { - Knowledge } \\
\text { - Competencies } \\
\text {-e-Portfolio } \\
\text { (productions) }\end{array}$ \\
\hline
\end{tabular}

Personal sub-profile is used to store personal information that does not change over the time, information such as name, family name, etc. The learning sub-profile is used to store information such as preferences of teaching methods and learning styles. As for the professional sub-profile of the learner model, it represents the knowledge, goals, competencies and productions (e-portfolio). Such a subprofile is used to manage the production of the learner and to establish links between its objectives and its achievements. We have based on the standard IMS-LIP and Felder and Silverman model for modeling ontology of learners. The following figure shows an overview of this ontology edited by the Protégé 2000 tool.

\section{MODELLING THE TRAININGS ACCORDING TO THE COMPETENCY- BASED APPROACH}

The competency-based approach is not only the acquisition of resources (knowledge, skills and attitudes), but also their integration for solving problems more or less complex. A competency can be decomposed into more specific components, called "competencies levels» [20]. In the context of this paper, we consider a level of competence as a period of training that focuses on developing a specific competency component of the general. Each specific competence is composed of a number of operational competencies and it is considered developed only after the success of the learner in the phase of the integration of resources in resolving problem situations. Operational competence is developed through the implementation of all operational objectives that compose it; no integration is envisaged at this stage.

\subsection{Towards An Enveloping Taxonomy}

To model the professional training based on competencies approach, we proposed an enveloping taxonomy that has two phases: the phase of the acquisition of resources supporting the implementation of punctual learning, and the problemsolving phase favoring the development of competencies. This new taxonomy includes the six levels of Bloom and the four categories of Paquette, Table 2.

This taxonomy is established on the basis of the complementarily of the two approaches in order to develop learners' competencies gradually. Starting first, by installing resources for the purpose of achieving goals for exercising capacities of low level, and chaining after that, by the problem solving capacity to exercise high level capacities. These later are exerted by special problem situations called: situations of integration (SI). They are also called complex situations, and involve significant and complex issues related to the life of the learner. These situations must compel the learner to mobilize his knowledge and his expertise to be solved. They are used to exercise when assessing skills following a process that includes the following phases: (i) analysis a problem, (ii) organize the steps of resolution, (iii) make a critical judgment on each step. Therefore, two key steps are necessary for the development of competence in a given taxonomy:

Step 1: Installing resources by adopting the approach by objectives, such as, the concepts to understand must be formulated in the form of operational objectives. This formulation is done by applying low-level capacity content (Knowledge, Understanding and Application).

Step 2: Solving a problem situation of integration by mobilizing the necessary resources that are assumed. This step allows the learner to exercise jurisdiction under the parallel and high-level skills, also called soft skills (Analysis, Synthesis and Evaluation). The skills have to be made in the form of a high-level taxonomic objective. The challenge for the learner is at the identification of internal and external resources required for problem solving. They thus learn to do the analysis, synthesis and evaluation. 


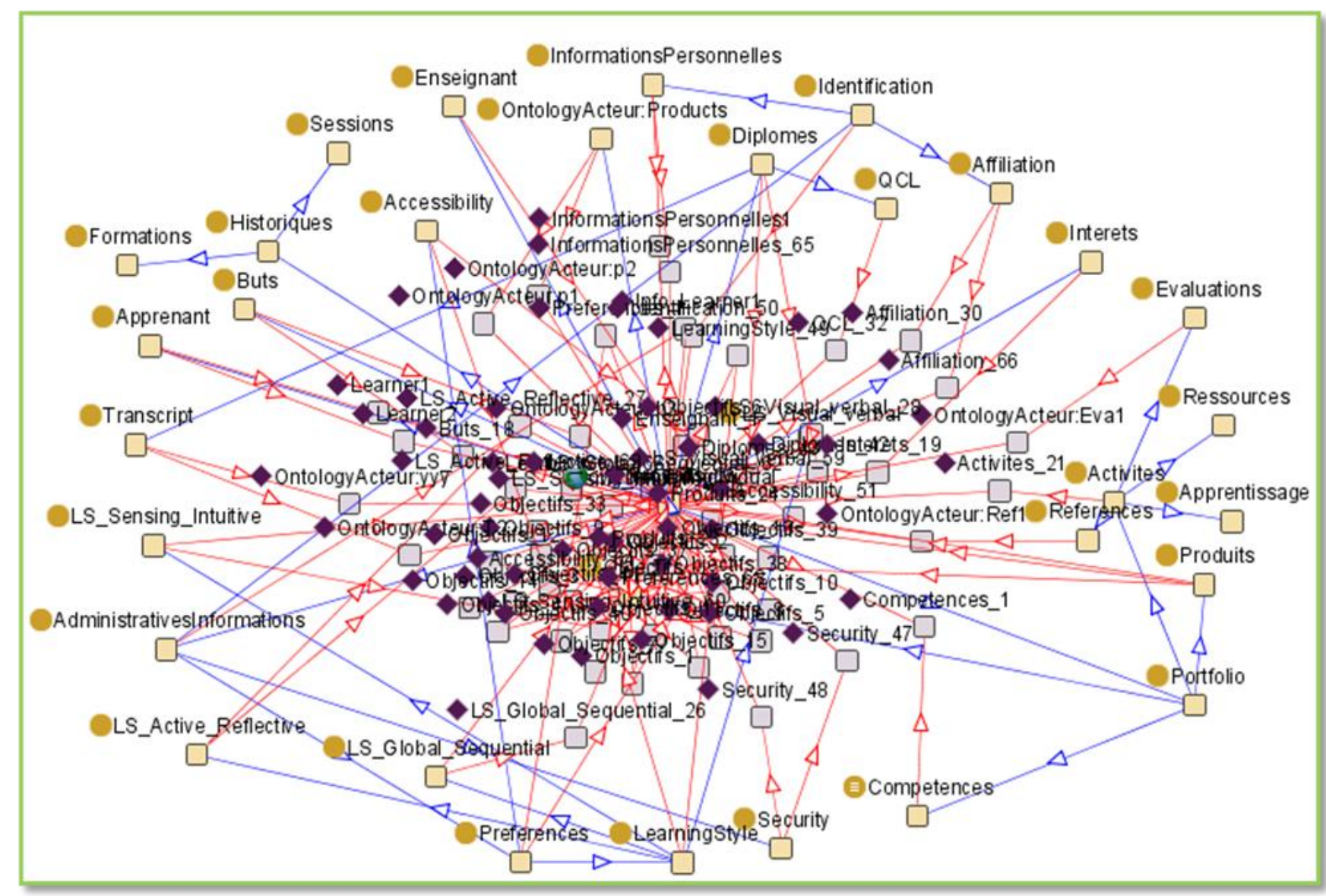

Fig 1: Learners Ontology integrating their preferences and production 
Table 2 Wrap taxonomy of two pedagogical approaches

\begin{tabular}{|c|c|c|c|c|c|}
\hline $\begin{array}{l}\text { Level of } \\
\text { capacity }\end{array}$ & Bloom taxonomy & Paquette taxonomy & Wrap taxonomy & Pedagogical approach & $\begin{array}{l}\text { Type of } \\
\text { capacity }\end{array}$ \\
\hline 1 & Knowledge & Reception & \multirow{3}{*}{$\begin{array}{l}\text { Resource } \\
\text { Acquisition }\end{array}$} & \multirow{3}{*}{ By objectives } & \multirow{3}{*}{ Low level } \\
\hline 2 & Comprehension & \multirow{2}{*}{ Reproduction } & & & \\
\hline 3 & Application & & & & \\
\hline 4 & Analysis & \multirow{2}{*}{ Production } & \multirow{3}{*}{$\begin{array}{l}\text { Problems } \\
\text { resolution }\end{array}$} & \multirow{3}{*}{ By competencies } & \multirow{3}{*}{ High leve } \\
\hline 5 & Synthesis & & & & \\
\hline 6 & Evaluation & Self-management & & & \\
\hline
\end{tabular}

\subsection{Operationalization Of A General Competence}

The implementation of general competency must be done through four levels [19]. Each level is designed to achieve a level of operationalized competency by a specific competency. The latter is divided into two main periods (the first is the resource installation and the second is the resource integration).The following figure shows the structure of a general competence.

Level 1: takes place in two phases: the installation of resources $\{\mathrm{R} 1\}$ and resolving the situations of integration mobilizing in an integrated manner and wisely the resources of the level in question (SI $\{\mathrm{R} 1\}$ );
Level2: takes place in two phases: the installation of resources $\{R 2\}$ and solving the situations of integration that are more complex than these of level 1 , mobilizing in an integrated manner and wisely the resources of level 1 and 2 (SI $\{\mathrm{R} 1$, $\mathrm{R} 2\})$.

Idem for levels 3 and 4; whenever the resources of a level are installed, their integration comprises both the resources of the current level and those of the upstream levels.

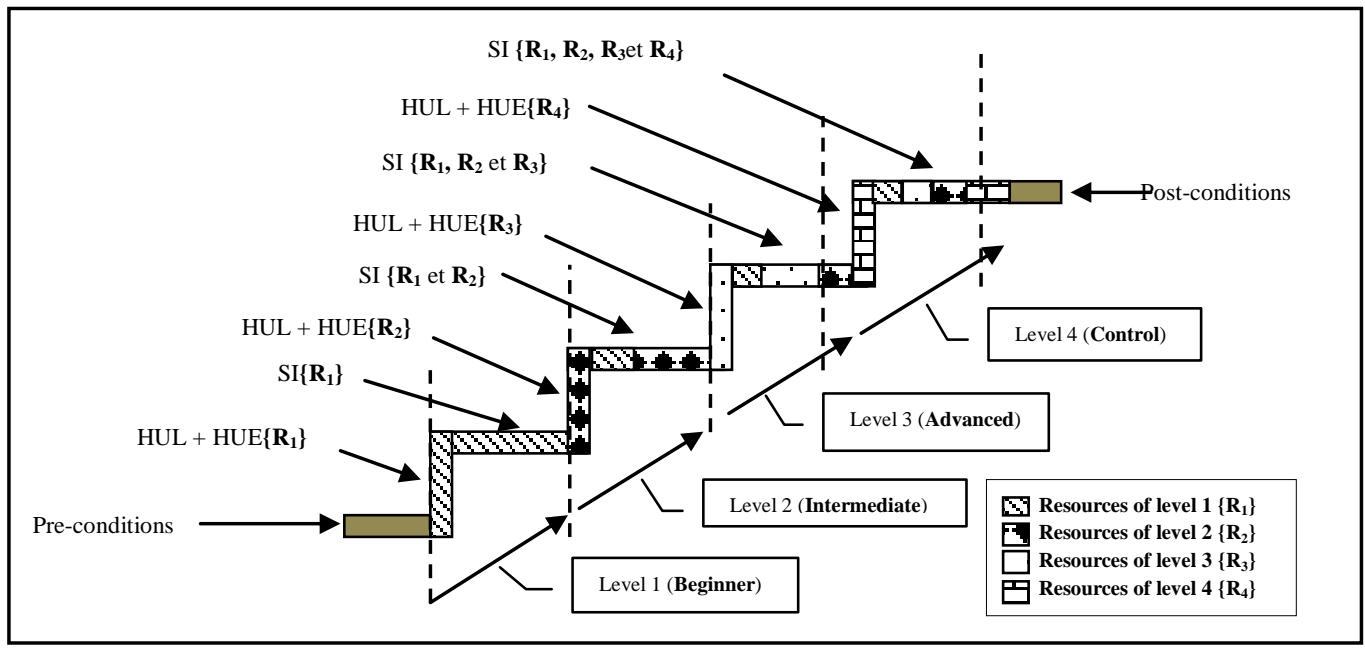

Fig 2: Structuring a competency by levels

Pre-conditions: whom are the conditions of entry to acquire a competency (they correspond to the input profile, to check with a diagnostic evaluation).

Post-conditions: whom are the conditions of validation of competency (they correspond to the output profile to be verified by a certification evaluation).

\subsection{Ontological Modelling}

Ontologies are considered the dorsal technology of the semantic web. They are widespread in the field of knowledge management. As part of this solution, we developed two ontologies (resources ontology and competencies ontology) for modelling professional training based on competency approach:

- The ontology of resources for the organization of educational resources. It's based on the concept of hypermedia unit (UH), hypermedia unit is used in the installation phase of the resources and their integration. To ensure the reuse of hypermedia units and define their context of use, a semantic description is associated to each hypermedia unit. The hypermedia units can be reused in several learning paths, this reuse is ensured by defining three levels of description: pedagogical level, educational level and technical level [2].

- The competencies ontology for the representation of competencies of a training. Trades of the teaching and education are learned progressively in the process of integrating theoretical and practical knowledge strongly articulated to each other. The Ministry of the National Education published the decree establishing the competency referential of teachers in CRMEF of Morocco. This text focuses on the professionalism of the trade and meets all the teachers' specialities.

In addition, to model a competency, several standards and specifications have been proposed. IMS-RDCEO (Reusable Definition of Competencies and Educational Objectives) is best known for formally represent the main characteristics of 
a competency, independently of its use in any particular context. This specification consortium [23] defines an information model for describing, referencing and exchanging definitions of competencies for learning in online and distributed environments. Characteristics proposed by the IMS-RDCEO model for modelling a competency does not allow to come up to all the criteria expected. To do this, we have added other elements while keeping the mandatory elements of the IMS specification to ensure the possibility of reusability and sharing among learning systems adopting the IMS model. The following figure shows an overview of the competencies ontology developed:

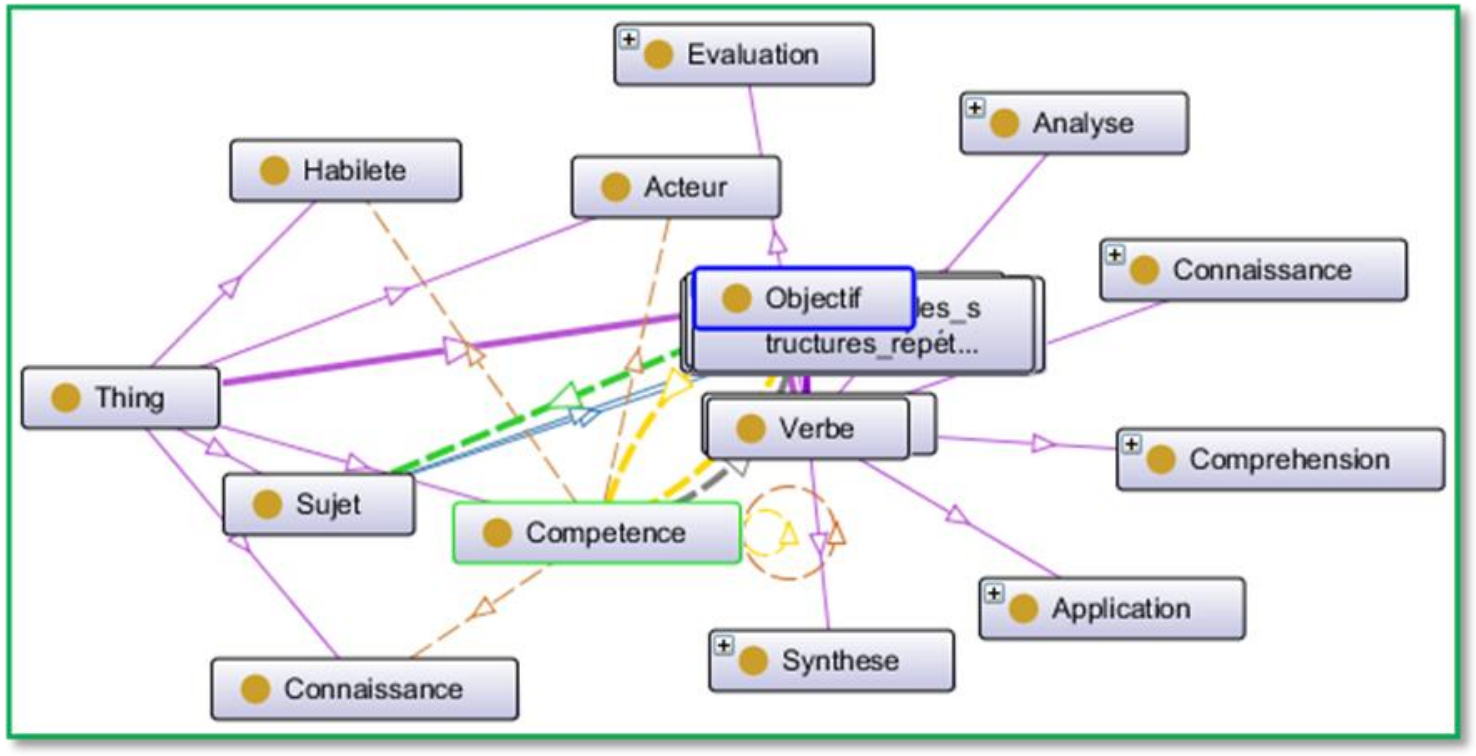

Fig 3: Overview of competencies Ontology

\section{LEARNING SCENARIOS AND FUNCTIONALITIES OF THE SOLUTION}

The proposed system offers two modes of training: (a) a guided mode that compels the learner to execute pedagogical scenarios to acquire general competencies and (b) a free mode allowing learners in difficulties to overcome their problems. To illustrate the first mode, we proposed a global scenario (Figure 4) and a scenario to clarify the process of the resources installation (Figure 5).The second mode gives learners the flexibility to choose and acquire an operational objective or a specific competency. This mode is used often by learners to overcome problems by taking advantage of adaptive solution [3] and [1].

\subsection{The General Competency Acquisition Scenario}

This scenario aims to present the process of acquiring general competency. Competency is developed through four stages that allow a learner to achieve respectively the four levels: basic, intermediate, advanced and master (Figure 3). The planning of training is defined by instructional designers based on the relationship "is Prerequisite Of" and "is Composed Of" that binds the targeted competencies.

The process of developing a competency begins with a diagnostic assessment as MCQ to check whether the learner masters the prerequisites. If it fails, the system will offer him a learning path of support and reinforcement and redo the test until the learner has the necessary bases.

The student who passes this step, proceed to the resources installation process of the first level, taking advantage of the potential of the proposed adaptive solution [3].To exit the level, the learner must solve integration problems situations through two main phases: training phase and certification evaluation phase. If the learner passes the certification test, he proceeds to the next step to install new resources and solve more complex situations. And finally, to validate his acquisitions and have his certificate, the student must pass a certification evaluation in his institution (eg CRMEF).The following figure shows the different phases followed by the learner to acquire a general competence.

\subsection{Scenario Of The Installation Of A Level's Resources}

This scenario presents the resources installation process of a level of general competency. To do this, the learner is expected to acquire operational competencies embodied by operational objectives. For each objective, the system provides the learner with appropriate adaptive and punctual learning session composed of two hypermedia learning units: one for learning (HUL) and the other for the formative evaluation (HUE).The embodiment of a test object is based on application exercises. The student who fails his goal could benefit from another more appropriate HUL. The system includes the result of the evaluation as another parameter of adaptation. If the objective in question is considered complete, the system will present the following teaching unit taking advantage of the principle of evolutionary learning paths [21].The objectives of operational competence do not give the learner empowerment to acquire the next skill because this passage is determined by its success in an assessment presented as synthesis exercises. These exercises are simple problems situations favouring the linkage of different HUL. This allows developing learners' capacity for analysis and synthesis. If the student fails the final test, the system will offer him a remedial session, otherwise it moves to the next operational competence. Once the resources are installed, the learner is passed to the phase of resources integration. The figure 5 shows the resources installation phase. 


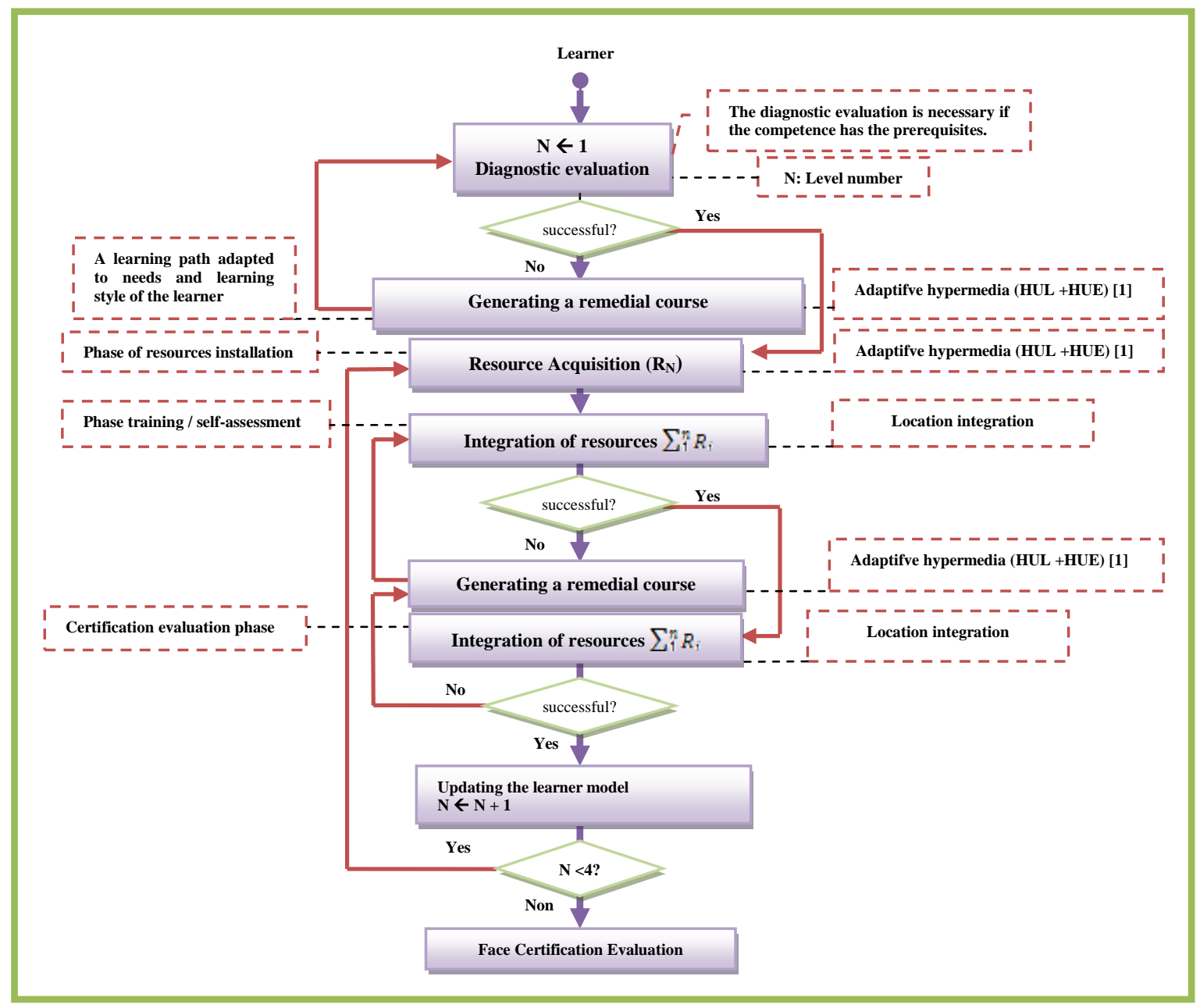

Fig 4: A global Scenario

\section{EVALUATION OF LEARNING SESSIONS AND TUTORING}

In this section we present the way in which learning sessions are evaluated and how are they helped learners in case of difficulty. First, the process of resources integration, which aims to transform learners' acquisitions in real competencies, is spread over two main phases: (a) training phase and (b) certification evaluation phase (figure 6). The training phase is reserved for learning and enables learners to manage their learning and selfevaluate their product. It takes place over six stages:

- Understanding phase: In this stage the learner receives assistance from a human and / or software tutor to understand the situation of integration (reactive Tutoring). The tutor shall provide the learner characteristics of the expected product and provides additional resources if needed.

- Production phase: In this stage the learner mobilizes its resources to resolve the situation of integration question.

- Self-Assessment phase: This is a stage where the learner carries a reflexive and critical look at the product based on an evaluation grid provided by the tutor.

- Improvement phase: In this phase the learner improves its product and provides a available to tutor for correction.

- Correction phase: In this stage, the tutor uses the assessment grid communicated to the learner to correct the deliverable given back. It diagnoses the learner errors and identifies the difficulties encountered in order to preparing remediation activities. If the learner provides the minimum required, it will move to the phase of the certification evaluation to close the level in question.

- Remedial phase: this stage is for students in difficulties. These later benefit from adapted hypermedia units to correct their weaknesses [21]. After remediation, the system offers the learner another integration situation which is similar to the first to redo the training phase in order to continue his learning.

The certification evaluation phase is to assess the degree of master of the target level (basic, intermediate, advanced or master) of the specific competency. During this phase, no aid is given to the student by the tutor for the resolution of problem situations. In other words, the certification evaluation takes place in three stages:

- Production Step: In this step the learner mobilizes its resources to resolve the situation of integration issue and produce a deliverable.

- Correction Step: in this phase, the responsible teacher corrects the product of learner in order to detect mistakes and identify the gaps to propose remedial tracks. If the learner reaches the minimum level required, it will go to the next step and an update of its model will be made by the system. This update concerns its competencies and its deliverables. 
- Remediation Step: This step is for students in difficulties. After remediation, the system returns the learner to the training phase.

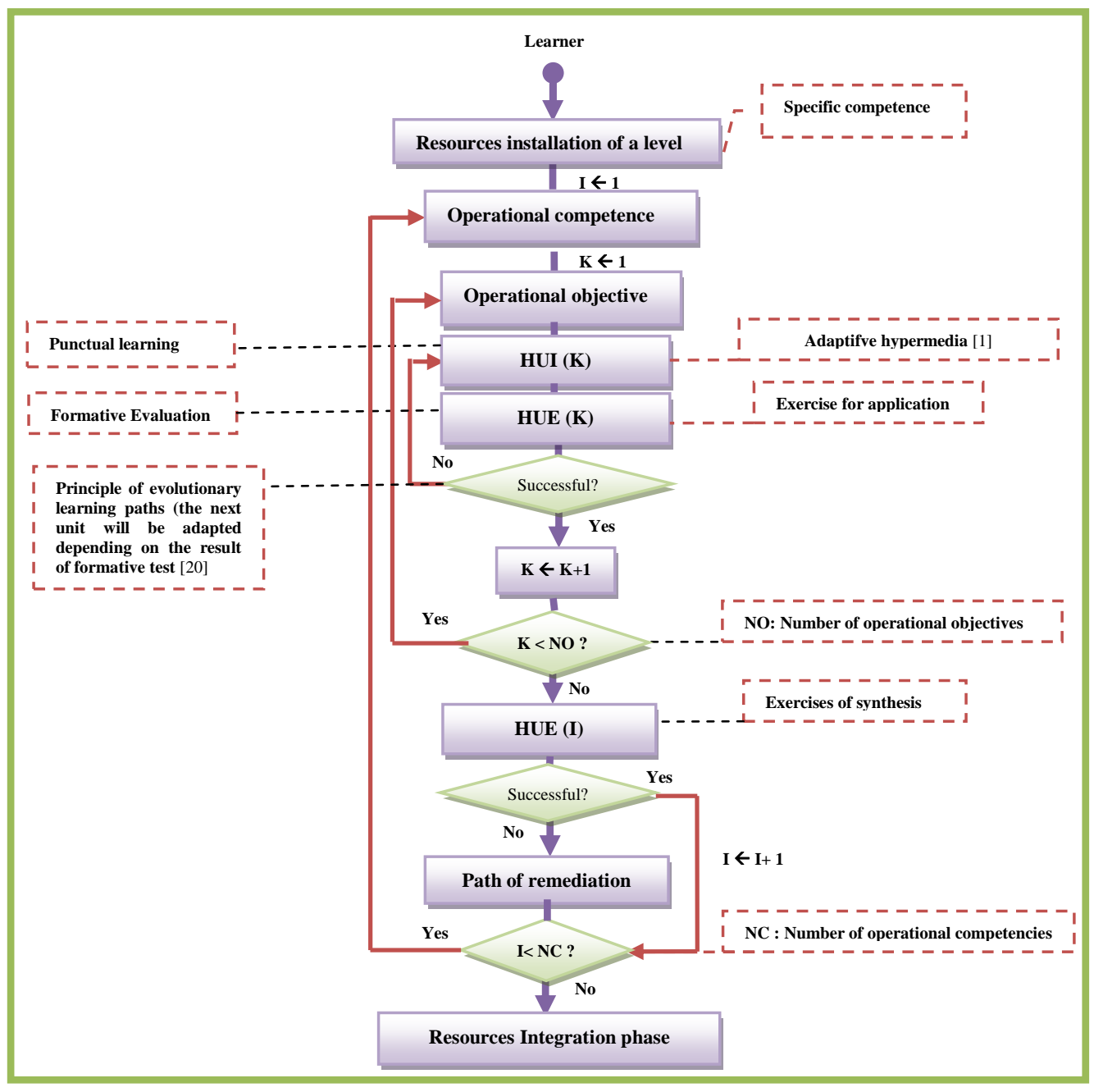

Fig 5: Resources Installation Scenario 


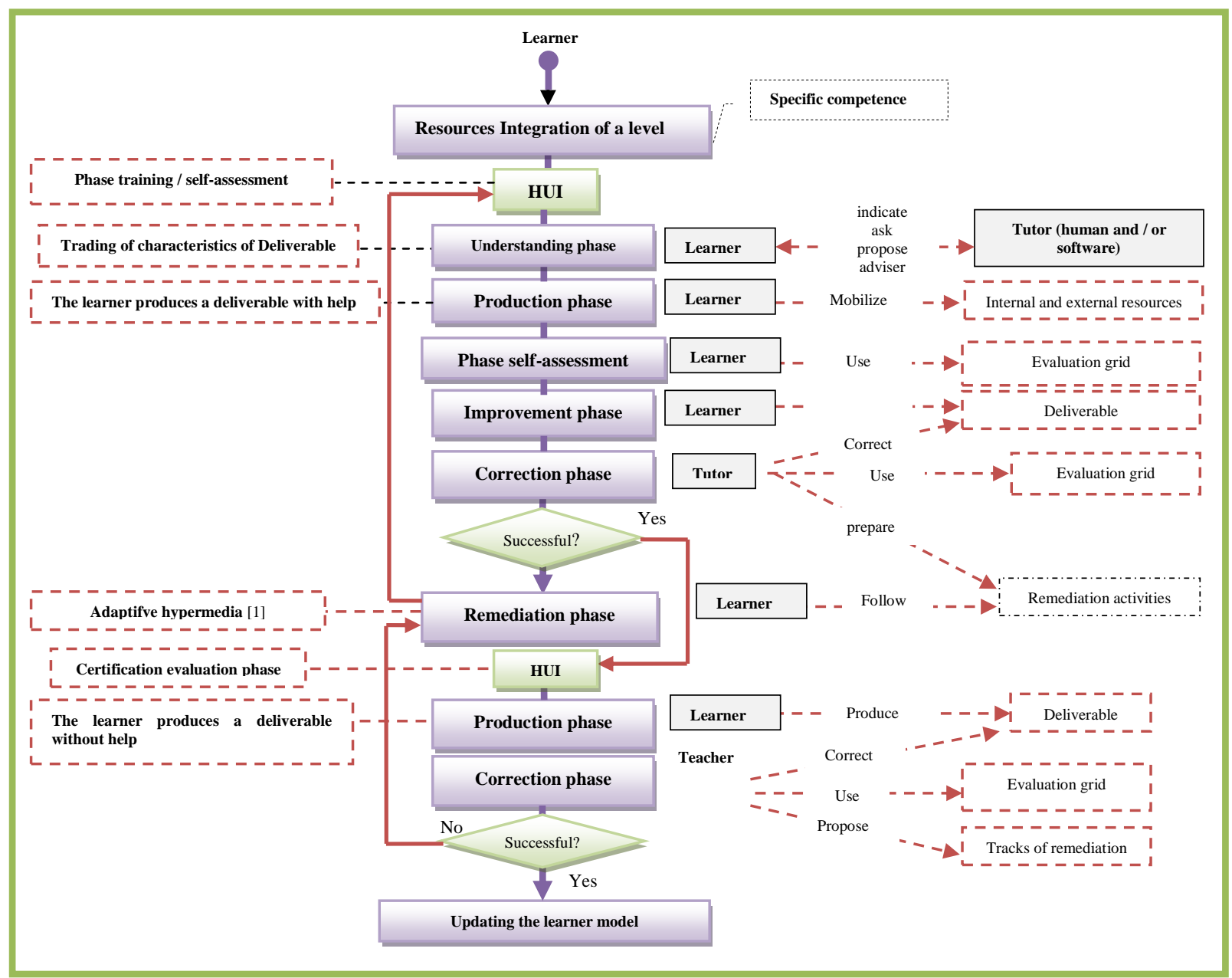

Figure 6: Resources Integration Scenario 


\section{CONCLUSION}

In this paper we proposed a solution based on ontological engineering and competency approach for modelling professional training. The proposed solution offers learners two access modes: free mode where the learner can target a specific level of competence, and a guided mode where the learner must follow the steps proposed by the system in the context of professional training. Each training session consisted of two phases: the first is that of the installation of the resources where learners benefit from online tutoring and the adaptation of learning paths, and the second is the integration phase where learners must be able to mobilize installed resources to solve problem situations more or less complex. Remedial paths are available to learners in difficulties in order to fill their gaps. The deliverables of each learner are stored in his e-Portfolio for later exploitation. In perspective, we consider the deliverables of learners as a real rich data base to make inferences and deduce other parameters contributing to the success or the failure of the learners.

\section{REFERENCES}

[1] J. El Bouhdidi, M. Ghailani, A.Fennan "An Intelligent Architecture For generating Evolutionary Personalized Learning Paths Based On Learner Profiles", Journal of Theoretical and Applied Information Technology (JATIT), Vol 57. Num2, November 2013.

[2] J. El Bouhdidi, M. Ghailani, A.Fennan "Towards an Optimized Design of Individualized Learning Paths: an Approach Based on Ontology and Multi-agents System", International Journal Of Computer Science Issues, Vol.9, Issue 6, No 3, November 2012.

[3] M. GHAILANI, J. EL BOUHDIDI, A.FENNAN "Integration of semantic web in e-learning platform to generate appropriate learning paths" (PP. 464-469), International Journal of Advanced Computer Science (IJACSI), December Issue, Vol 2, No 12, 2012.

[4] Mohamed GHAILANI, Jaber EL BOUHDIDI, Abdelhadi FENNAN "Design of an e-learning model providing appropriate pedagogical services" (PP. 23-26), Journal of Communications and Computer Engineering (JCCE), December Issue, Vol 2, No 2 (2012).

[5] van Merriënboer, J.J.G. et Kirschner, P.A. (2007). Ten Steps to Complex Learning: A Systematic Approach to Four-component Instructional Design. Mahwah, NJ: Erlbaum.

[6] Sluijsmans, D.M.A., Straetmans, G.J.J.M. et van Merriënboer, J.J.G. (2008). Integrating authentic assessment with competence-based learning in vocational education: the Protocol Portfolio Scoring. Journal of Vocational Education \& Training, 60 (2), 159-172.

[7] Paquette, G. (2002a). L'ingénierie pédagogique: Pour construire l'apprentissage en réseaux. Sainte-Foy (Québec): Presses de l'Université du Québec.

[8] Paquette, G. (2002b). Modélisation des connaissances et des compétences. Sainte-Foy (Québec): Presses de l’Université du Québec.

[9] Paquette, G. et Magnan, F. (2007). Learning Resource Referencing, Search and Aggregation at the eLearning System Level. Paper presented at the Proceedings of $1^{\text {st }}$
International Workshop on Learning Object Discovery \& Exchange (LODE'07) at $2^{\text {nd }}$ European Conference on Technology Enhanced Learning (EC-TEL07), Crete, Greece. [En ligne]. Consulté le 30 Mars 2013. http://fire.eun.org/lode2007/lode04.pdf

[10] Paquette, G. et Magnan, F. (2008). From a Conceptual Ontology to the TELOS Operational System. Paper presented at the ITS Workshop on "Ontology-based Learning Resource Referentials". [En ligne]. Consulté le $30 \quad$ Avril 2013 http://www.licef.ca/Portals/29/docs/pub/onto/ITS08\%20 LORNET\%20paper.pdf

[11] Moulet, L., Marino, O., \& Hotte, R. (2006). Holistic evolving and multi-viewpoints learner model. Actes de la conference I2LOR-06, Third annual scientific conference - LORNET Research Network. Montréal Canada.

[12] http://www.lornet.ca/Portals/10/I2LOR06/23 Holistic,\% 20Evolving\%20and\%20Multiviewpoints\%20\%20Learner\%20Model.pdf

[13] Basque, J. et Page-Lamarche, V. (2007). Un outil d'autodiagnostic des compétences au service d'une approche multi-scénarios pédagogiques dans un cours à distance... ou lorsque la différenciation pédagogique cesse d'être un mythe. In Actes du colloque Scénario 2007 - Scénariser les activités de l'apprenant: une activité de modélisation ( $2^{\mathrm{ième}}$ Colloque international sur les scénarios pédagogiques), Montréal, 14-15 mai 2007 (pp. 77-81). Montréal : LICEF, Télé-université.

[14] Hotte, R., Basque, J., Page-Lamarche, V. et Ruelland, D. (2007). Ingénierie des compétences et scénarisation pédagogique. Revue internationale des technologies en pédagogie universitaire, 4(2), 38-56. [En ligne]. Consulté le $\quad 30 \quad$ avril 2013. http://www.ritpu.org/IMG/pdf/ritpu0402_hotte_basque.p df

[15] Basque, J., Ruelland, D. et Lavoie, M.-C. (2007). A digital tool for self-assessing information literacy skills. In T. Bastiaens et S. Carliner (Eds.), Proceedings of the E-Learn 2007, World Conference on E-Learning in Corporate, Government, Healthcare, \& Higher Education, Quebec City, October 16-19, 2007 (pp. $6997-$ 7003). Chesapeake, VA: Association for the Advancement of Computing in Education (AACE). [En ligne]. Consulté le 30 Avril 2013. http://biblio.teluq.uqam.ca/Portals/691/docs/pdf/Digital.p $\underline{\mathrm{df}}$

[16] Jacques Raynauld, Olivier Gerbé, Nicole Téta Nokam, 2012. Référentiels de compétences [En ligne]. Consulté le $\quad 30 \quad$ Mai $2013 . \quad$ http://www.gtnquebec.org $/ \mathrm{moa} /$ publications/rapport/referentielscompetences/

[17] Tardif J. (2006). L'évaluation des compétences. Documenter le parcours de développement. Montréal : Chenelière Education

[18] Le Boterf, Guy (2011), Ingénierie et évaluation des compétences, Eyrolles, 6e édition, $605 \mathrm{p}$

[19] Deletstre N., METADYNE, un hypermédia adaptatif dynamique pour l'enseignement, Thèse de l'université de Rouen (France). 
[20] X. Roegiers, Une pédagogie de l'intégration : compétences et intégration des acquis dans l'enseignement. De Boeck, Bruxelles (2000).

[21] J. El Bouhdidi, M. Ghailani, A.Fennan "A Probabilistic Approach for the Generation of Learning Sessions Tailored to the Learning Styles of Learners" International Journal of Emerging Technologies in Learning(i-JET) Volume 8, Issue 6, December 2013.

[22] Mohamed Dali, Le schéma directeur de la réforme de la formation initiale des enseignants au Maroc, Accès : http://superieur.deboeck.com/resource/extra/9782804169 077/Annexe3.pdf

[23] Oubahssi, L., « Conception de plates-formes logicielles pour la formation à distance, présentant des propriétés d'adaptabilité à différentes catégories d'usagers et d'interopérabilité avec d'autres environnements logiciels ». Thèse de Doctorat en informatique, Université René Descartes Paris V. 